\title{
INFORMUOTO PACIENTO SUTIKIMO ATLIKTI ANESTEZIJĄ GAVIMO PRAKTIKA IR ANESTEZIJOS KOMPLIKACIJU VERTINIMAS LIETUVOS ANESTEZIOLOGŲ-REANIMATOLOGU POŽIŪRIU
}

\author{
Tomas Jovaiša ${ }^{1}$, Lukas Gambickas ${ }^{2}$, Miglè Kalinauskaite் ${ }^{2}$, Evaldas Kauzonas ${ }^{2}$, Ieva Norkiene் ${ }^{2}$ \\ ${ }^{1}$ Lietuvos Sveikatos mokslu universiteto Anesteziologijos klinika, \\ ${ }^{2}$ Vilniaus universiteto Medicinos fakulteto Anesteziologijos ir reanimatologijos klinika
}

Raktažodžiai: informuoto asmens sutikimas, anesteziologija.

\begin{abstract}
Santrauka
Informuoto asmens sutikimas tampa vis svarbesnis kasdieneje anesteziologo praktikoje dèl nuolat didẻjančių reikalavimų sveikatos apsaugos standartams. Tačiau šiuo metu nèra vieningos formos. Dažnai anesteziologai, remdamiesi savo patirtimi, patys nusprendžia, apie kokias anestezijos rizikas kalbèti su pacientu, o tokia praktika neatitinka šiuo metu propaguojamos irodymais grịstos medicinos reikalavimų. Šio tyrimo tikslas buvo ịvertinti informuoto asmens sutikimo atlikti anesteziją gavimo praktiką ir anestezijos komplikacijų vertinimą tarp Lietuvos anesteziologų.

Atlikta savanoriška ir anoniminè anesteziologų-reanimatologų apklausa. Respondentai turejjo atsakyti i klausimus apie sutikimo atlikti anesteziją gavimo praktiką jų darbovietėje bei atskleidžiančius jų žinias apie informuoto paciento sutikimą.

Apklausą užpildè 146 respondentai. Respondentų demografiniai duomenys atspindejo Lietuvos anesteziologų-reanimatologų bendruomenès demografinę sudètị. Bemaž $90 \%$ pacientų pasirašo sutikimą tą pačią dieną prieš operaciją. $91 \%$ respondentų teigé, kad pacientai neperskaito formoje nurodytos informacijos, bet tik $32 \%$ mane, kad tai yra todèl, kad jų naudojama sutikimo atlikti anesteziją forma per daug sudètinga. Dauguma gydytojų nurodè nuo 6 iki 20 kartų didesni sunkių anestezijos komplikacijų dažnį, nei nurodoma tarptautineje literatūroje ir vidutiniškai tik $17,3 \%$ pateike tikslius atsakymus. Tik 43,8\% respondentų mano, kad esama sutikimo atlikti anesteziją forma apsaugo gydytoją skundų ir teisinio
\end{abstract}

nagrinejjimo atvejais.

Informuoto asmens sutikimo atlikti anesteziją procedūra Lietuvoje dažnai neatitinka saugios anestezijos reikalavimų. Gydytojai yra linkę pervertinti komplikacijų riziką, todèl pacientams pateikiama informacija gali ženkliai skirtis. Reikalinga nauja sistema, kuri leistų užtikrinti pilnavertišką paciento sutikimą atlikti anesteziją.

\section{İvadas}

Šiandieninè medicinos praktika neatsiejama nuo teisinio reguliavimo. Vienas būdų užtikrinti teikiamų sveikatos apsaugos paslaugų teisètumą yra informuoto asmens sutikimas (IAS). Ši dokumentą privalu patvirtinti paciento parašu prieš ivvairias sveikatos sistemoje teikiamas paslaugas, kadangi tik rašytinis asmens sutikimas yra laikomas teisètu [1]. Lietuvoje galiojantis Paciento teisių ir žalos sveikatai atlyginimo ịstatymas (PTŽSAI ) griežtai apibrèžia IAS gavimo taisykles ir nurodo, jog pacientui teikti sveikatos priežiūros paslaugas be jo sutikimo yra draudžiama [2]. Vis dèlto, kalbant apie IAS gavimo praktiką anesteziologijoje, literatūroje vis dažniau ginčijama tokio dokumento gavimo tvarka ir būtinumas $[3,4]$. Viena vertus, anestezija, kaip ir bet kokia kita procedūra, turi savų rizikų, apie kurias pacientą privalu informuoti, kad galètų tinkamai nuspręsti tokios intervencijos būtinumą. Kita vertus, dažniausiai anestezija yra taikoma pacientams chirurginių operacijų metu, kurios nebūtų ịmanomos be gydytojo anesteziologo teikiamų paslaugų [1]. Nagrinejant pačią IAS anesteziologijoje gavimo praktiką keliamas dar vienas klausimas: ar IAS gavimo vieta ir laikas yra tinkami. Remiantis literatūros duomenimis, sutikimas, gautas tą pačią dieną kaip ir atliekama procedūra, gali būti ginčytinas teisme, kadangi pacientas tuo metu gali būti susijaudinęs ir tinkamai neapsvarstyti jam kylančių procedūros grèsmių. Taip pat ne tik stresas, bet ir laiko stoka gali daryti itakos 
tokiam sprendimui, kadangi nepakankamai susipažistama su pateikiama informacija [1]. Šiuolaikinès galimybès ir nuolat tobulejjančios gydymo gairès leido sumažinti itin pavojingų anestezijos komplikacijų (tokių kaip mirtis) dažnị iki mažai reikšmingo, kai ši procedūra taikoma „lengvos“ fizinès klasès pacientui (ASA I) [5]. Duomenys rodo, kad paciento informavimas apie tokio pobūdžio riziką sukelia jam papildomo nerimo [1].

Tyrimo tikslas: ivvertinti informuoto asmens sutikimo anestezijai gavimo praktiką Lietuvoje.

\section{Tyrimo medžiaga ir metodai}

Savanoriška ir anoniminė gydytojų apklausa. Apskaičiuotas imties dydis buvo 83 respondentai, remiantis šiomis nuostatomis: Lietuvoje aktyviai dirbančių anesteziologų-reanimatologų skaičius ( $\mathrm{n}=650)$, patikimumo intervalas $95 \%$ ir paklaidos riba, neviršijanti 10\%. Pirmoje klausimyno dalyje gydytojai turejo nurodyti duomenis, susijusius su profesine kvalifikacija ir darbo pobūdžiu. Antroje anketos dalyje sie- kėme įvertinti gydytojų žinias apie ypač sunkias anestezijos komplikacijas. Trečioje klausimyno dalyje respondentai turejjo pateikti savo nuomonę apie jų praktikoje naudojamą sutikimo formą ir sutikimo procedūrą.

Surinktų duomenų apdorojimas ir statistinè analizè buvo atlikti Microsoft Excel ir SPSS programomis. Neskaitinių kintamujų statistinei analizei buvo taikomas $\chi^{2}$ metodas, tęstinių skaitinių kintamujų analizei Stjudento (Student) t-testas. Komplikacijų dažnis vertintas pagal atsakymų medianą. Rezultatų skirtumas buvo laikytas statistiškai reikšmingu, jei gauta p reikšmė buvo mažesnè nei 0,05 .

\section{Rezultatai}

Tyrime dalyvavo 146 respondentai. Respondentų demografiniai duomenys pateikiami 1 lentelèje.

Remiantis apklaustujų duomenimis, dažniausiai naudojama atskira, ligonineje patvirtinta sutikimo atlikti anesteziją forma ir dažniausiai patys gydytojai gauna sutikimus atlikti anesteziją. Absoliuti pacientų dauguma sutikimą atlikti
1 lentelè. Apklausos dalyvių demografiniai rodikliai.

\begin{tabular}{|c|c|c|}
\hline & $\begin{array}{c}\text { Respon- } \\
\text { dentų } \\
\text { skaičius }\end{array}$ & $\begin{array}{l}\text { Respon- } \\
\text { dentų \% }\end{array}$ \\
\hline \multicolumn{3}{|l|}{ Lytis } \\
\hline Vyrai & 49 & 33,6 \\
\hline Moterys & 96 & 65,8 \\
\hline Nenurodyta & 1 & 0,7 \\
\hline \multicolumn{3}{|l|}{ Darbo stažas (metai) } \\
\hline $0-2$ & 11 & 7,6 \\
\hline $3-5$ & 36 & 24,7 \\
\hline $6-10$ & 19 & 13 \\
\hline $11-20$ & 37 & 25,4 \\
\hline $21-30$ & 25 & 17,1 \\
\hline$>30$ & 17 & 11,6 \\
\hline \multicolumn{3}{|l|}{ Amžius (metai) } \\
\hline $25-34$ & 46 & 31,5 \\
\hline $35-44$ & 38 & 26,0 \\
\hline $45-54$ & 34 & 23,3 \\
\hline $55-64$ & 25 & 17,1 \\
\hline$>64$ & 3 & 2,1 \\
\hline \multicolumn{3}{|l|}{ Profesinė kvalifikacija } \\
\hline Gydytojas rezidentas & 19 & 13,1 \\
\hline Gydytojas & 111 & 76,0 \\
\hline $\begin{array}{l}\text { Gydydytojas konsul- } \\
\text { tantas }\end{array}$ & 16 & 11,0 \\
\hline
\end{tabular}

2 lentelè. IAS atlikti anesteziją praktika Lietuvoje.

\begin{tabular}{|c|c|c|}
\hline & $\begin{array}{c}\text { Respondentų } \\
\text { skaičius }\end{array}$ & $\begin{array}{l}\text { Respon- } \\
\text { dentų \% }\end{array}$ \\
\hline \multicolumn{3}{|c|}{$\begin{array}{l}\text { Kokia sutikimo atlikti anesteziją forma naudojama jūsų gydymo ịs- } \\
\text { taigoje? }\end{array}$} \\
\hline Atskiras, ligoninejje patvirtintas, dokumentas & 124 & 84,9 \\
\hline $\begin{array}{l}\text { Bendras patvirtintas sutikimas atlikti anesteziją } \\
\text { ir operaciją }\end{array}$ & 19 & 13,0 \\
\hline Laisva forma, įrašas ligos istorijoje & 2 & 1,4 \\
\hline \multicolumn{3}{|c|}{ Kuris specialistas informuoja pacientą ir pasirašo sutikimą? } \\
\hline Anesteziologas, pats atliksiantis anesteziją & 115 & 78,8 \\
\hline Operuosiantis chirurgas & 4 & 2,7 \\
\hline Ambulatorinio vizito metu & 1 & 0,7 \\
\hline Neatsakè & 26 & 17,8 \\
\hline \multicolumn{3}{|c|}{ Kur ir kada pacientas pasirašo sutikimą atlikti anesteziją } \\
\hline $\begin{array}{l}\text { Ambulatorinio apsilankymo metu prieš hos- } \\
\text { pitalizaciją }\end{array}$ & 6 & 4,1 \\
\hline Palatoje prieš operaciją & 120 & 82,2 \\
\hline Operacinèje/paruošimo patalpoje & 3 & 2,1 \\
\hline $\begin{array}{l}\text { Kita (arba aukščiau išvardintų variantų de- } \\
\text { rinys) }\end{array}$ & 14 & 9,6 \\
\hline \multicolumn{3}{|c|}{ Ar sutikimo formoje yra nurodomos anestezijos komplikacijos? } \\
\hline Taip & 130 & 89,0 \\
\hline $\mathrm{Ne}$ & 12 & 8,2 \\
\hline Neatsakè & 4 & 2,7 \\
\hline \multicolumn{3}{|c|}{ Kaip aprašomos komplikacijos sutikimo formoje? } \\
\hline $\begin{array}{l}\text { "Visos nejautrai būdingos" (nenurodant kon- } \\
\text { krečių komplikacijų) }\end{array}$ & 111 & 76,0 \\
\hline $\begin{array}{l}\text { Aptariama ir įrašoma kiekviena komplikacija } \\
\text { atskirai }\end{array}$ & 5 & 3,4 \\
\hline Neatsakè & 30 & 20,5 \\
\hline
\end{tabular}


anesteziją pasirašo palatoje prieš operaciją ir retais atvejais operacinejje. Daugumoje respondentų naudojamų sutikimo formų yra minimos anestezijos komplikacijos, deja, dažniausiai nenurodant konkrečių komplikacijų ar jų dažnio. Detalūs šios apklausos dalies rezultatai pateikiami 2 lentelëje.

3 lentelè. Respondentų nurodytų anestezijos komplikacijų dažnių (procentais) mediana ir palyginimas su literatūroje nurodytais dažniais. $\mathrm{SN}$ - standartinis nuokrypis.

\begin{tabular}{|l|c|c|c|}
\hline & $\begin{array}{c}\text { Mediana \% } \\
( \pm \mathbf{S N})\end{array}$ & $\begin{array}{c}\text { Literatūroje nu- } \\
\text { rodomi dažniai } \\
\mathbf{\%}\end{array}$ & $\begin{array}{c}\text { Paklaida } \\
\text { (kartais) }\end{array}$ \\
\hline Dantų pažeidimas & $1( \pm 12)$ & $0,05-0,15$ & 6 \\
\hline Anafilaksija & $0,2( \pm 8)$ & $0,005-0,01$ & 20 \\
\hline $\begin{array}{l}\text { Budrumas aneste- } \\
\text { zijos metu }\end{array}$ & $0,2( \pm 4)$ & $0,1-0,7$ & Tikslu \\
\hline Mirtis & $0,01( \pm 1,4)$ & $0,0004-0,0007$ & 14 \\
\hline
\end{tabular}

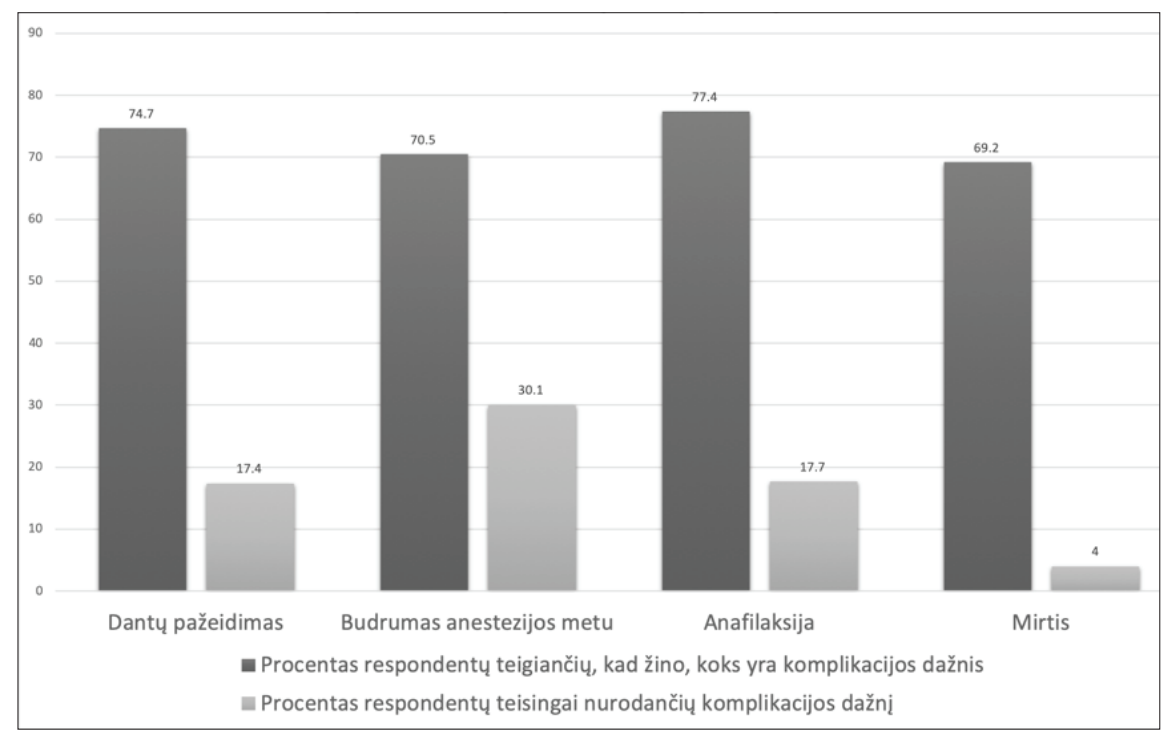

1 paveikslas. Žinių apie komplikacijos dažnius variabilumas.

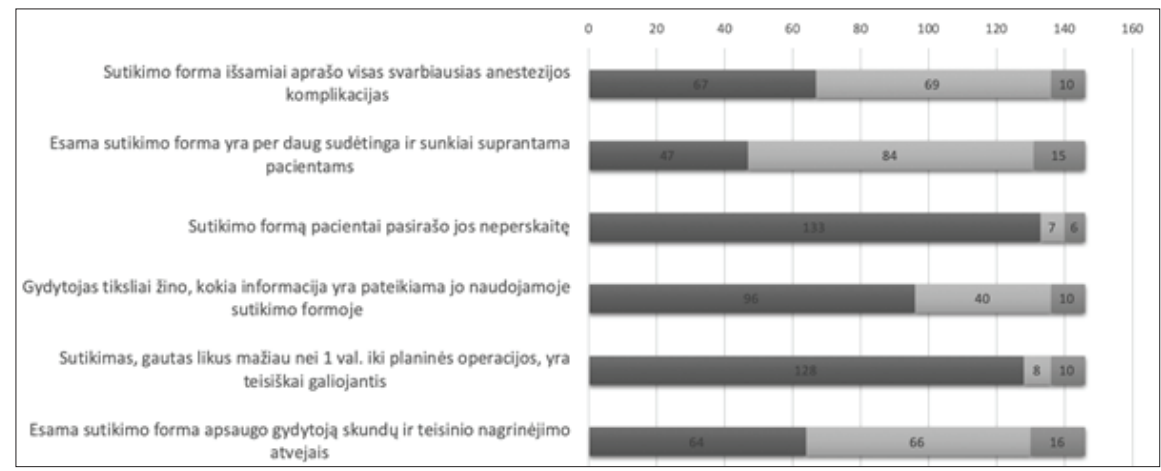

2 paveikslas. Gydytojų nuomonè apie jų naudojamas sutikimo formas.
Didžioji respondentų dalis teigè žinantys nurodytų bendrosios anestezijos (BA) komplikacijų dažnius, tačiau tik nedidelè dalis atsakymų sutapo su tarptautinèje literatūroje skelbiamais procentais. Mūsų apklausos duomenimis, anesteziologai yra linkę pervertinti komplikacijų dažnius ir dažniausiai nurodo nuo keleto iki keliasdešimt kartų didesnę riziką. Detalūs šios apklausos dalies duomenys pateikti 1 paveiksle ir 3 lentelèje. Jaunieji gydytojai (stažas iki 5 metų) yra statistiškai patikimai labiau linkę pasitikèti savo žiniomis negu vyresni kolegos. Didesnis jaunujų nei vyresniujju gydytojų procentas teige žinantis komplikacijų dažnius (dantų pažeidimas $\mathrm{p}=0,047$; anafilaksija $\mathrm{p}=0,028$; budrumas anestezijos metu $\mathrm{p}=0,046$; mirtis $\mathrm{p}=0,007$ ). Tačiau lyginant jaunesniujjų ir vyresniujų gydytojų pateiktus atsakymus ir lyginant juos su tarptautiniais šaltiniais skirtumo tarp amžiaus grupių nebuvo ( $p>0,05)$. Kiti mūsų tirti kintamieji nebuvo susiję su žiniomis apie komplikacijų dažnị (lytis, amžiaus grupės, kvalifikacija, komplikacijų nurodymo būdas, $\mathrm{p}>0,05$ ).

Tik $46 \%$ anesteziologų teigé, kad jie išsamiai aprašo visas komplikacijas. Trečdalis anesteziologu mano, kad IAS forma yra per daug sudètinga ir sunkiai suprantama pacientams. Vis dèlto, respondentų nuomone, naudojamos IAS formos sudetingumas statistiškai reikšmingai nepriklausè nuo jos išsamumo $(\mathrm{p}=0,249)$. Net $91 \%$ respondentu teigè, kad jų pacientai pasirašo sutikimo atlikti anesteziją formas jų neperskaitę, tačiau beveik toks pats procentas respondentų tiki, kad tokia, prieš pat operaciją gauta sutikimo forma, yra juridiškai galiojanti. Detalūs šios apklausos dalies rezultatai pateikiami 2 paveiksle.

\section{Diskusija}

Siuolaikinèje medicinoje itin svarbu siekti gauti paciento sutikimą prieš kiekvieną diagnostinę, intervencinę procedūrą [3]. Tai padeda užtikrinti paciento autonomiją - gebejjimą pačiam priimti svarbius sprendimus savo gyvenime [13]. Pagrindiniai IAS principai yra: adekvatus informavimas, kompetentingas pacientas, savanoriškas sutikimas bei dinamiškumas (gali- 
mybė bet kada atšaukti sutikimą) [3]. Tačiau dažnai pastebima, kad pacientai ne visada gali apibūdinti rizikas, apie kurias juos turejjo informuoti gydytojai [18]. Lietuva nèra išimtis. Remiantis mūsų apklausos duomenimis, dauguma gydytojų yra įsitikinę, kad pacientai pasirašo asmens sutikimą jo neperskaitę, o tai prasilenkia su PTŽSAI 15 str. $5 \mathrm{~d}$. ìstatais [2]. Respondentų nuomonè apie sutikimo formas yra labai kritiška, dažniausiai jos neatlieka nei pageidaujamos informacinès, nei sutikimo, nei juridinès apsaugos funkcijų. Informacijos kiekio ir pateikimo prieš procedūrą klausimas išlieka kontraversiškas. Daugejja įrodymų, kad per didelis informacijos kiekis didina priešoperacinio nerimo lygi [5]. Tuo metu nepakankamas paciento informavimas siejamas su paciento lūkesčiais ir blogesniu subjektyviu baigčių vertinimu $[1,14]$. Lietuvoje galiojantys teisès aktai teigia, kad gydytojas privalo informuoti pacientą ne tik apie tipines, bet ir apie specifines bei retai pasitaikančias komplikacijas [2]. Tačiau akivaizdu, kad istoriškai susiklosčiusi klinikinė praktika neleidžia išpildyti šių reikalavimų. Apklausa rodo, kad gydytojai linkę nurodyti ne visas komplikacijas ir nurodyti labai plačias komplikacijų rizikos ribas. Tai gali būti susiję su skirtingų informacijos šaltinių naudojimu, konkrečios gydymo ịstaigos statistika ar tendencija pervertinti riziką. Remiantis apklausos rezultatais galima teigti, kad būtina vieninga sistema, kuri padètų kuo geriau informuoti pacientą bei užtikrinti tinkamą teisinę apsaugą gydytojui, pateikusiam informaciją.

\section{Išvados}

Informuoto asmens sutikimo atlikti anesteziją procedūra Lietuvoje dažnai neatitinka saugios anestezijos reikalavimų. Gydytojai yra linkę pervertinti komplikacijų riziką, todèl pacientams pateikiama informacija gali ženkliai skirtis. Būtina nauja sistema, kuri leistų užtikrinti visavertišką paciento sutikimą atlikti anesteziją.

\section{Literatūra}

1. White SM, Baldwin TJ. Consent for anaesthesia. Anaesthesia 2003.

https://doi.org/10.1046/j.1365-2044.2003.03202.x

2. I-1562 Lietuvos Respublikos pacientų teisių ir žalos sveikatai atlyginimo įstatymas.

3. Bowman D, Spicer J, Iqbal R. Informed consent: a primer for clinical practice 2011. https://doi.org/10.1017/CBO9781139057523

4. Gruodyte E., Šalčiūtė-Pratkienė L. Informuoto paciento sutikimo doktrinos samprata ir svarba sveikatos priežiūroje. Law Rev, 2013.

5. Cyna AM, Simmons SW. Guidelines on informed consent in anaesthesia: unrealistic, unethical, untenable.... Br J Anaesth 2017. https://doi.org/10.1093/bja/aex347

6. Tan Y, Loganathan N, Thinn KK, Liu EHC, Loh N-HW. Dental injury in anaesthesia: a tertiary hospital's experience. BMC Anesthesiol 2018.

https://doi.org/10.1186/s12871-018-0569-6

7. Maria GR, Paolo F, Stefania B, Letizia T, Martina A, Massimiliano D, ir kt. Traumatic dental injuries during anaesthesia: part I: clinical evaluation. Dent Traumatol 2010.

8. Freundlich RE, Duggal NM, Housey M, Tremper TT, Engoren $\mathrm{MC}$, Kheterpal S. Intraoperative medications associated with hemodynamically significant anaphylaxis. J Clin Anesth 2016. https://doi.org/10.1016/j.jclinane.2016.09.023

9. Sandin RH, Enlund G, Samuelsson P, Lennmarken C. Awareness during anaesthesia: a prospective case study. Lancet 2000. https://doi.org/10.1016/S0140-6736(05)73124-X

10. Cook TM, Andrade J, Bogod DG, Hitchman JM, Jonker WR, Lucas N. et al. The 5th National Audit Project (NAP5) on accidental awareness during general anaesthesia: patient experiences, human factors, sedation, consent and medicolegal issues. Anaesthesia 2014.

https://doi.org/10.1111/anae.12827

11. Jenkins K, Baker AB. Consent and anaesthetic risk. Anaesthesia 2003.

https://doi.org/10.1046/j.1365-2044.2003.03410.x

12. Haller G, Laroche T, Clergue F. Morbidity in anaesthesia: today and tomorrow. Best Pract Res Clin Anaesthesiol 2011.

https://doi.org/10.1016/j.bpa.2011.02.008

13. Delany C. Making a difference: incorporating theories of autonomy into models of informed consent. J Med Ethics 2008. https://doi.org/10.1136/jme.2007.023804

14. Fortunato JT, Wasserman JA, Menkes DL. When respecting autonomy is harmful: a clinically useful approach to the nocebo effect. Am J Bioeth 2017.

https://doi.org/10.1080/15265161.2017.1314042

15. Krauss BS. "This may hurt": predictions in procedural disclosure may do harm. BMJ 2015.

https://doi.org/10.1136/bmj.h649

16. Samaranayake UMJE, Mathangasinghe Y, Banagala ASK. Are predominantly western standards and expectations of informed consent in surgery applicable to all? A qualitative study in a tertiary care hospital in Sri Lanka. BMJ Open 2019.

https://doi.org/10.1136/bmjopen-2018-025299

17. General Medical Council. Consent: patients and doctors making decisions together. London: General Medical Council 2008.

18. Lühnen J, Mühlhauser I, Steckelberg A. The quality of informed consent forms a systematic review and critical analysis. Dtsch Arzteblatt Int 2018.

https://doi.org/10.3238/arztebl.2018.0377

19. Sriubas M. Paciento teisių užtikrinimo ir pareigų ịtvirtinimo problemos Lietuvoje. Justitia, 2009. 


\section{INFORMED CONSENT FOR ANAESTHESIA: CURRENT PRACTICES AND ANAESTHESIA RISK ASSESSMENT AMONG LITHUANIAN ANAESTHESIOLOGISTS - REANIMATOLOGISTS T.Jovaiša, L.Gambickas, M.Kalinauskaitė, E.Kauzonas, I.Norkienė}

Keywords: informed consent, anaesthesia Summary

Introduction. The practice of anaesthesia is becoming increasingly challenging due to rising standards of care, thus it increases the importance of informed anaesthesia-specific patient consent. However, there is a significant variation in the practice of consent worldwide. Anaesthesiologists often use their clinical judgment in deciding which anaesthesia risks to discuss with patients leaving evidence-based medicine behind. The purpose of this study was to determine the practices and opinions of Lithuanian anaesthesiologists regarding informed consent.

Materials and Methods. A voluntary and anonymous survey. Participants received questions concerning their daily practice obtaining informed consent for anaesthesia as well as questions regarding the incidence of major anaesthetic complications. Data processing and statistical analysis were performed using MS Excel and SPSS.

Results. A total of 146 questionnaires were eligible for processing. Demographics of the survey cohort is reflective of Lithuanian anaesthetic community. Nearly $90 \%$ of patients give informed consent on the day and shortly before their surgery. $91 \%$ of respondents stated that patients do not read the information provided in the consent form, however, only $32 \%$ though that this is due to the complex form and information. Referring to risks of major anaesthetic complications (dental damage, anaphylaxis, awareness and anaesthesia related death), majority of practitioners indicated 6 to 20 fold higher incidences compared to those published previously and on average only $17,3 \%$ of answers fell within the predetermined reference range. Only $43,8 \%$ of respondents believed that the current form of informed patient consent would be useful in case of complaints or legal challenges.

Conclusion. The practice of informed patient consent for anaesthesia often falls short of the expected standard. Physicians tend to overstate the associated risks, therefore there is likely significant variation in the information provided to the patients. There is a need for a major change in practice to ensure that all the aspects of informed consent are met.

Correswpondence to: ievanork@gmail.com

Gauta 2019-07-19 